\title{
NILAI-NILAI PENDIDIKAN DALAM TOR-TOR NAPOSO NAULI BULUNG
}

\author{
Meiliza Hijrati ${ }^{1}$, Siti Rahmah ${ }^{2}$ \\ Prodi Pendidikan Tari/ Fakultas Bahasa dan Seni/ Universitas Negeri Medan \\ Jalan Willem Iskandar Pasar V Medan Estate 20221, Sumatera Utara-Indonesia \\ Imeilizahijrati@gmail.com, ${ }^{2}$ rahmaiyen@yahoo.co.id,
}

\begin{abstract}
This study aims to describe Educational Values in Tor-Tor Naposo Nauli Bulung. Theories used in this study include value theory and educational theory. The method used in this research is descriptive qualitative method. The population of this research are South Tapanuli people in Mabar Hilir and Deli Serdang, and the sample of this research are 3 South Tapanuli people in Deli Serdang and Mabar Hilir. In the discussion of this study as for the focus of my research is using the theory of religious values according to Abdul (2012: 129) and moral values according to Sutardjo (2011: 54). This study aims to describe the educational values in Tor-Tor Naposo Nauli Bulung. Data collection in this research is done by observation method, interview, documentation, and analysis technique. This study discusses the explanation of the values of education contained in Tor-Tor Naposo Nauli Bulung for dancers and the public to know that in a dance there are also good values that can be a positive value in everyday life and can be used as material teachers for learners. The results of the research can be seen that in Tor-Tor Naposo Nauli Bulung, contained the values of education in which viewed from the pattern of motion, fashion, music, and rules. The values are peeled through religious values and moral values which can then be used as a source of information to the community and the dancers that there are values that can be used as learning can also be used as teacher material for learners.
\end{abstract}

Keyword: Value, Education, Religious Value, Moral Value, Tor-Tor Naposo Nauli Bulung

\section{PENDAHULUAN}

Kabupaten Mandailing Natal yang sering disebut dengan Madina adalah sebuah Kabupaten yang berada di Provinsi Sumatera Utara. Di Kabupaten Madina ini terdapat beberapa Kecamatan, salah satunya yaitu Kecamatan Pakantan. Kecamatan Pakantan adalah sebuah Kecamatan yang terletak di Hulu sungai Gadis (Batang Gadis), dilereng Gunung Kulabu diwilayah Kabupaten Mandailing Natal paling selatan. Kecamatan Pakantan terdiri dari delapan "huta" (desa) yaitu Huta Dolok, Huta Gambir, Huta Lancat, Huta Lombang, Huta Padang, Huta Toras, Huta Julu, dan silogun.
Masyarakat Pakantan dikenal dengan beragam kesenian seperti seni musik dan tari. Seni musik antara lain yaitu gordang sambilan dimana kesenian ini memang asli berasal dari Kabupaten Mandailing Natal dan tari yaitu tortor. Memahami tentang tor-tor dalam masyarakat ini memerlukan pengenalan terhadap masyarakat Pakantan desa huta gambir sebagai masyarakat Madina dikenal dengan kesenian yang tidak terlepas dari nilai-nilai afektif, kognitif, serta norma adat yang berlaku didalam pelaksanaannya.

Salah satu kesenian tersebut yaitu seni tradisi seperti seni tari. Berbicara tentang tari tradisi, tor-tor menjadi kesenian khas 
masyarakat Mandailing Natal. Pada masyarakat Madina, tor adalah sebutan untuk bukit. Sumber lain menjelaskan bahwa istilah tor tu tor dapat mengandung pengertian yang melukiskan suatu keadaan atau hal-hal tertentu, dimana dari bukit yang satu ke bukit-bukit yang lainnya. Dapat ditarik kesimpulan bahwa tampak garis seperti bukit yang berbentuk segitiga yang terlihat turun naik yang berkaitan dengan gerakan dalam tortor. Dimana para penari yang menarikan tampak seperti naik turun.

Secara luas, Tor-tor dalam masyarakat madina bukan hanya sebagai tari, tetapi juga sebagai media untuk bersosialisasi dilingkungan masyarakat Mandailing. Motif gerak yang dilakukan dalam tor-tor adalah komunikasi interaksi antara partisipan upacara yang mengandung rasa persaudaraan, solidaritas untuk kepentingan bersama dan prinsip kebersamaan. Sesuai dengan sistem kekerabatan yang dipakai dalam masyarakat tersebut.

Adapun yang menjadi fokus penelitian saya yaitu Tor-tor Naposo Nauli Bulung. Berdasarkan yang telah diteliti oleh beberapa sumber, Tor-tor Naposo Nauli Bulung merupakan Tor-tor yang sudah ada sejak zaman dahulu, namun tidak diketahui siapa penciptanya. Tor-tor Naposo Nauli Bulung merupakan salah satu Tor-tor yang terdapat dalam pesta perkawinan. Tor-tor ini sering disebut dengan tor-tor muda-mudi yang ditarikan secara berpasangan laki-laki dan perempuan. Posisi perempuan yang berada didepan bernama na isembar dan posisi laki-laki yang berada dibelakang bernama panyembar dengan catatan tidak boleh satu marga antara laki-laki dan perempuan.

Dalam menarikan Tor-tor Naposo Nauli Bulung, jumlah penari tidak ditentukan, namun harus dilakukan secara berpasangan laki-laki dan perempuan. Tor-tor ini bentuknya sangat tradisi, dilihat dari ragam geraknya yang sederhana, menggunakan pola lantai melingkar dan sejajar, serta iringan musik yang lambat sehingga sifatnya monoton. Adapun motif gerak dari tortor ini yaitu Manyomba Tu Raja (hormat kepada raja), Markusor (berputar), Singgang (jongkok), dan hormat penutup. Busana yang dipakaiantara lain laki-laki memakai baju dan celana panjang, sarung, memakai арpu (tutup kepala/peci) dan ulos godangnya yang diselempangkan menutupi bahu, sedangkan untuk perempuan memakai baju kurung dan mengenakan jarunjung (sejenis sunting),

Iringan musik yang digunakan dalam tor-tor ini yaitu gondang, suling, ogung, dan momongan atau tali sayak. Pada pelaksanaan upacara adat, penggunaan gondang dan tor-tor selalu berjalan bersama. Fungsinya yang utama adalah untuk menyampaikan rasa hormat, baik kepada yang maha kuasa, juga kepada orangorang yang dihormati seperti individu sesuai tingkat sosialnya dalam sistem kekerabatan dan tamu yang diundang.

Selain dipertunjukan pada upacara adat perkawinan, Tor-tor Naposo Nauli Bulung juga dapat dijadikan sebagai media pendidikan yang memuat nilai-nilai ajaran bagaimana cara seseorang bersikap patuh terhadap Tuhan Yang Maha Esa, rendah diri, peduli, saling 
menghargai, mengormati, sopan, santun, bekerja sama, silaturahmi dan lain sebagainya. Juga terdapat aturan dan pesan yang bisa disampaikan oleh orang tua kepada anaknya, pendidik kepada peserta didik, dan menjadi pemahaman tersendiri oleh para pelaku tari. Mengingat kondisi yang sekarang, kurangnya kesadaran individu terhadap fungsi tari sebagai media pendidikan.

Peranan pendidikan sangat penting untuk menciptakan kehidupan yang lebih baik didalam kehidupan kita. Karena pendidikan berkaitan dengan sikap kita terhadap Tuhan Yang Maha Esa, diri sendiri, keluarga, guru, budaya, adat istiadat dan lingkungan kita. Dengan demikian didalam tarian/tor-tor tersebut ada nilai-nilai pendidikan yang memberikan pesan kebaikan yang dijadikan sebagai pembelajaran. Dalam hal ini yang dapat dilihat dari bentuk penyajian serta bentuk tor-tor naposo nauli bulung. Adapun bentuk yang akan dilihat melaui elemen-elemen tari seperti lintas gerak, busana, iringan musik, dan tempat pertunjukan. Maka dari itu penulis tertarik ingin mengkaji lebih dalam dan luas lagi mengenai nilai-nilai pendidikan dalam Tor-tor Naposo Nauli Bulung.

tujuan yang harus dicapai dalam penelitian ini adalah :

1. Mendeskripsikan bentuk Tor-tor Naposo Nauli Bulung.

2. Mendeskripsikan nilai pendidikan yang terkandung dalam Tor-tor Naposo Nauli Bulung.
Untuk membahas Nilai-Nilai Pendidikan dalam Tor-tor Naposo Nauli Bulung menggunakan teori Nilai Agama dan Nilai Moral.

Penelitian dilakukan di Mabar Hilir dan Deli Serdang Tanjung Selamat pada Masyarakat Mandailing Natal. Waktu Penelitian dilakukan pada Bulan Juni sampai dengan bulan September 2017.

Populasi dalam Penelitian ini adalah beberapa Tokoh Adat dan Tokoh Masyarakat, serta Seniman. Sampel dalam Penelitian ini adalah 1 orang Tokoh Adat, 1 orang Tokoh Masyarakat, dan 1 orang Seniman. Tekhnik Pengumpulan Data yang dilakukan adalah sebagai berikut: 1 . Observasi, 2. Wawancara, 3 . Dokumentasi, 4. Studi Kepustakaan. Dalam Penelitian ini data yang digunakan adalah deskriptif kualitatif dimana penelitian ini sesuai dengan fakta sosial dan memberi gambaran, keterangan serta uraian.

\section{HASIL DAN PEMBAHASAN}

\section{Tor-tor Naposo Nauli Bulung}

Pertunjukan Tor-tor Naposo Nauli Bulung hanya diadakan berkaitan dengan upacara perkawinan dan merupakan Tor-tor yang sudah ada sejak zaman dahulu. Disertakannya tor-tor dalam rangkaian upacara adat, seiring dengan aturan dalam sisitem kekerabatan yang menjadi panduan masyarakat, sehingga tidak diketahui siapa penciptanya. Tortor ini sering disebut dengan tor-tor muda-mudi yang ditarikan secara berpasangan laki-laki dan perempuan, dan dilakukan oleh kaum muda 
yang belum menikah. Posisi perempuan yang berada didepan bernama na isembar dan posisi laki-laki yang berada dibelakang bernama panyembar dengan catatan tidak boleh satu marga antara laki-laki dan perempuan.

\section{Nilai Pendidikan dalam Tor-Tor}

\section{Nilai Religius}

Nilai religius yang dimaksudkan dalam pembahasan ini adalah suatu proses pembelajaran dalam kehidupan masyarakat dimana suatu kesenian dapat menciptakan hubungan yang harmonis antara makhluk dengan sang khalik/pencipta dan hubungan antar sesama manusia dan hubungan manusia dengan alam. Sesuai dengan tujuan pertunjukannya, tor-tor Naposo Nauli Bulung memiliki nilai-nilai yang dapat dilihat dari adanya hubungan antara manusia dengan tuhan yang dapat diamati dari susunan tarian. Berawal dari ragam gerak pertama dilakukan dengan hormat pembuka, seperti ungkapan somba do muloni tor-tor (awal mula tor-tor adalah sembah) yang memiliki makna segala sesuatu pekerjaan harus dimulai dengan memohon keridhoan ilahi untuk menjaga keselamatan dari segala sesuatu yang mengganggu. Permohonan pada Allah SWT harus menjadi susunan awal, sehingga pola gerak sombah menjadi susunan pertama penyajian. Penghormatan harus diberikan kepada Allah SWT untuk mendapatkan berkah, rahmat dariNya, serta untuk menjaga hati dari kesombongan, takabur, agar pelaksanaan kegiatan naposo dapat berjalan dengan baik. Sikap penyerahan diri menjadi hal mutlak dan aturan dalam susunan manortor. Permohonan tidak hanya kepada Tuhan semesta Alam, maaf juga diminta kepada yang terlihat maupun tidak terlihat, serta memberi hormat kepada raja-raja atau orang yang dituakan. Sombah menjadi keharusan yang berisi bilamana ada salah di dalam berdiri, bersikap, dan salah manortor, sehingga wajib bagi kita untuk bersika sopan santun yang harus tetap dijaga dengan memberi rasa hormat.

Selain hubungan dengan Tuhan, dalam Tor-tor Naposo Nauli Bulung juga tertuang ajaran tentang sikap antara sesama manusia yang dapat dilihat dari sikap kaum muda masyarakat Madina dalam mengikuti proses kegiatan dimulai perencanaan, pelaksanaan, hingga akhir kegiatan. Pada awal perencanaan, kaum muda (pihak laki-laki) turut membantu kegiatan upacara dengan melakukan berbagai hal yang berkaitan dengan upacara, seperti mempersiapkan tempat pelaksanaan, menjaga keamanan yang akan memberikan ketenangan bagi para tamu yang datang. Kaum muda harus bertanggungjawab dengan pekerjaan yang sudah dibebankan dan merupakan bukti rasa patuh, tanggungjawab pada perintah yang sudah diberikan.

\section{Nilai Moral}

Nilai moral ini menjadi pendidikan bagi masyarakat untuk semua kalangan tidak hanya tertumpu pada kaum muda saja. Nilai moral tersebut antara lain tertuang dalam ragam-ragam gerak yang tersusun dalam urutan manortor. Ragam gerak hormat pembuka sebagai ragam pertama, kekuatan dalam tarian, terlihat pada 
gerak Laki-laki yang terbuka memiliki makna melindungi atau menjaga daripada boru tulangnya. Karena pada dasarnya laki-laki adalah seorang pemimpin yang bertanggungjawab didalam menjaga dan melindungi perempuan. Kemudian gerak perempuan dilakukan dengan ruang gerak kecil, menandakan bahwa perempuan harus menjaga sopan santun adab dan menjaga aurat.

Selanjutnya nilai norma tertuang juga pada ragam gerak markusor, yang memberikan makna kerja sama, silaturrahmi, dan gotong royong dalam membina keakraban dalam keluarga sanak saudara. Maka dipanggillah semua untuk bekerja sama. Walaupun pekerjaan bisa dilakukan dengan sendiri atau bisa dikerjaan berdua, tetapi dalam kehidupan masyarakat madina untuk menjaga keakraban silaturrahmi, mereka dengan beramai-ramai bekerjasama melakukan suatu pekerjaan untuk menjaga, menambah ukuwah persaudaraan. Selanjutnya pada ragam lingkaran (dalihan na tolu) yang sekaligus menjadi pola lantai lingkaran berkaitan dengan sistem kekerabatan masyarakat Mandailing yaitu Dalihan Na Tolu. Ragam ini menjelaskan bahwa setiap pekerjaan yang dilakukan selalu dengan musyawarah dan saling mencari kesepakatan yang baik didalam perencanaan. Dengan demikian terlihat bahwa peran dalihan na tolu yang menjadi pedoman bagi mereka. Peran ini menunjukkan komunikasi diantara ketiga posisi dari hula-hula, dongan tubu, dan anak boru, yang tampak dalam posisi lingkaran bermakna keberlanjutan hubungan mereka sebagai perangkat adat yang menjadi contoh bagi masyarakat (muda-mudi) untuk bersikap dalam kehidupan sehari-hari.

Pada ragam selanjutnya (singgang/ jongkok) juga memuat nilai moral yang menjelaskan tentang sebagai manusia haruslah menjaga sikap untuk selalu rendah hati, welas asih, tidak sombong, takabur dan mawas diri yang diberikan kepada Allah SWT, dan rajaraja, dan orang yang lebih tua. Juga ditunjukkan sebagai rasa syukur dan meminta doa kepada Sang Pencipta Semesta Alam agar diberi kelancaran dan keberkahan agar pelaksanaan adat dapat berjalan dengan lancar sesuai dengan yang diinginkan. Menjaga hal-hal yang tidak diinginkan menjadi tanggung jawab bagi diri sendiri agar terhindar dari marabahaya, dan segala hal yang dapat mengganggu. Sehingga pola singgang ini menjadi pola yang ada pada tortor naposo nauli bulung, juga sebagai perwujudan ajaran dalam Islam, agar setiap manusia untuk menjaga hal-hal yang dapat mencelakakan dirinya dan orang di sekelilingnya.

Dalam setiap kegiatan termasuk tarian, harus dimulai dengan pembuka dan diakhiri dengan penutup. Tor-tor naposo nauli bulung diawali dengan sombah kepada Allah swt dan diakhiri dengan sombah penutup yang menjelaskan akhir dari pertunjukan. Hal ini berkaitan dengan ajaran Islam bahwa memulai segala sesuatu diawali dengan "Bismillah" dan diakhiri dengan "alhamdulillah". Artinya dalam mengerjakan sesutua kita harus menyerahkan diri, tulus ikhlas mengerjakan agar hasil yang didapat sesuai dengan keinginan/harapan, dan 
setelah mendapatkan kita harus mengucapkan rasa syukur bahwa yang kita harapkan/inginkan dapat terlaksana. Dengan demikian sombah sebagai ungkapan penghormatan, rasa syukur, menjadi ungkapan yang harus ada dalam manortor.

Dari keseluruhan unsur utama maupun unsur pendukung tarian, kita dapat belajar banyak tentang kehidupan. Banyak ajaran-ajaran yang memuat kebaikan yang harus dipelajari sejak usia muda, agar dapat menjalani hidup dengan kebaikan, yang menuntut kita untuk besikap bijak untuk melaulinya.

\section{PENUTUP}

\section{Kesimpulan}

Tor-tor Naposo Nauli Bulung adalah tari yang berasal dari Kecamatan Pekantan Kabupaten Mandailing Natal Provinsi Sumatera Utara. Tor-tor Naposo Nauli Bulung adalah tarian yang ditarikan oleh muda-mudi secara berpasangan laki-laki dan perempuan dengan catatan tidak boleh satu marga. Tarian ini menceritakan tentang Anak boru yang menjaga Boru Tulangnya. Tarian ini terdapat dalam upacara perkawinan pada masyarakat Mandailing Natal.

Nilai-nilai pendidikan yang terdapat dalam tor-tor naposo nauli bulung menurut tahap penyajiannya adalah menghormati orang tua dengan meminta izin terlebih dahulu sebelum dilaksanakannya pesta perkawinan, kemudian dilihat dari ragam gerak, busana, dan musik dalam tor-tor naposo nauli bulung yaitu menghormati, sopan, santun, bekerja sama, perduli, toleransi, komunikatif, rendah hati, dan saling menghargai.

\section{Saran}

Berdasarkan penelitian mengenai nilai pendidikan dalam tor-tor naposo nauli bulung pada masyarakat Mandailing Natal maka peneliti memberikan saran sebagai berikut:

1. Tor-tor Naposo Nauli Bulung dapat menjadi salah satu media untuk menanamkan nilai-nilai pendidikan kepada para pelaku tari, anak sejak usia yang mulai beranjak dewasa baik dalam lembaga formal maupun non formal.

2. Untuk para pendidik khususnya dibidang seni tari agar lebih mengetahui nilai-nilai pendidikan yang terkandung dalam sebuah tari seperti salah satu kajian yang saya fokus kan yaitu tor-tor naposo nauli bulung agar menanamkan nilai-nilai pendidikan tidak hanya mengajarkan secara keterampilan saja.

\section{DAFTAR PUSTAKA}

Abdul, dkk, .2012. Dasar-dasar Pendidikan. Jakarta : Kencana

Danu Eka, 2015. Refleksi Pendidikan Indonesia. Yogyakarta : Ombak

Dermawan, dkk, 2015. Ilmu Sosial dan Budaya Dasar : Unimed Press

Dini Hariani, 2012. "Makna Simbol Tor-tor Naposo Nauli Bulung pada Masyarakat Simalungun". E-Journal of Unimed. Gesture : Jurnal Seni tari.

Ditin, 2015. Tor-tor Mandailing (info budaya). Artikel Budaya 
Dimyati \& Mudjiono. Belajar \& Pembelajaran: Rineka Cipta

Edward, Purba. 2014. Filsafat Pendidikan : Unimed Press

Eva Deni, 2012. "Tor-tor Upacara adat Masyarakat Tapanuli Selatan”. E-Journal of Unimed. Gesture : Jurnal Seni tari.

Hamid Darmadi, 2012. Dasar Konsep Pendidikan Moral. Bandung : Alfabeta

Mangunwijaya, 1982. Sastra dan Religius. Jakarta : Harapan

Muchson dkk, 2013. Dasar-dasar Pendidikan Moral Basis Pengembangan Pendidikan Karakter. Yogyakarta : Ombak.

Nanang Purwanto, 2014. Pengantar Pendidikan.Yogyakarta: Grahailmu

Rizki Nurjannah, 2017. "Pembelajaran Tot-tor Naposo Nauli Bulung menggunakan media audio visual pada kelas VII di MTS Negeri 1 Sibuhuan". E-Journal of Unimed. Gesture : Jurnal Seni tari.

RHD Nugrahaningsih \& Dilinar Adlin, 2014. Tor-tor Mandailing dan Pengembangannya. Medan : Unimed press

Robert Sibarani, 2012. Kearifan Lokal. Jakarta : Asosiasi Tradisi Lisan.

Robert Sibarani, 2015. Pembentukan Karakter. Jakarta : Asosiasi Tradisi Lisan.

Rohmat, Mulyana. 2011. Mengartikulasikan Pendidikan Nilai. Bandung: Alfabeta

Siswoyo, dkk, 2007. Ilmu Pendidikan Yogyakarta : UNY Press

Suyanto, 2010. Pendidikan Karakter. Jakarta : Rineka Cipta.

Sylvia Purnama, 2016. "Pendidikan Karakter dalam Tari Manduda pada Masyarakat Simalungun". E-Journal of Unimed. Gesture : Jurnal Seni tari.
Wardhana, Wisnoe. 1990. Pendidikan Seni Tari. Departemen Pendidikan Nasional.

Yulia, Citra. 2012. Pelaksanaan Pendidikan Karakter dalam Pembelajaran. E-Journal Universitas Negeri Padang. 